\title{
Current prevalence of multidrug-resistant organisms in long-term care facilities in the Rhine-Main district, Germany, 2013
}

M Hogardt (michael.hogardt@kgu.de) ${ }^{1}$, P Proba ${ }^{2}$, D Mischler ${ }^{3}$, C Cuny ${ }^{4}$, V A Kempf ${ }^{1}$, U Heudorf5,3

1. Institute for Medical Microbiology and Infection Control, University Hospital, Goethe-University, Frankfurt am Main, Germany

2. University of Giessen, Giessen, Germany

3. MDRO-Net Rhine-Main, Frankfurt am Main, Germany

4. Robert Koch Institute, National Reference Centre for Staphylococci and Enterococci, Wernigerode Branch, Germany

5. Public Health Department, City of Frankfurt am Main, Germany

Hogardt M, Proba P, Mischler D, Cuny C, Kempf VA, Heudorf U. Current prevalence of multidrug-resistant organisms in long-term care facilities in the Rhine-Main district, Germany, 2013. Euro Surveill. 2015;20(26):pii=21171. Available online: http://www.eurosurveillance.org/ViewArticle.aspx?Articleld=21171

Multidrug-resistant organisms (MDRO) and in particular multidrug-resistant Gram-negative organisms (MRGN) are an increasing problem in hospital care. However, data on the current prevalence of MDRO in long-term care facilities (LTCFs) are rare. To assess carriage rates of MDRO in LTCF residents in the German Rhine-Main region, we performed a point prevalence survey in 2013. Swabs from nose, throat and perineum were analysed for meticillin-resistant Staphylococcus aureus (MRSA), perianal swabs were analysed for extended-spectrum beta-lactamase (ESBL)-producing organisms, MRGN and vancomycin-resistant enterococci (VRE). In 26 LTCFs, 690 residents were enrolled for analysis of MRSA colonisation and 455 for analysis of rectal carriage of ESBL/MRGN and VRE. Prevalences for MRSA, ESBL/MRGN and VRE were $6.5 \%, 17.8 \%$, and $0.4 \%$, respectively. MRSA carriage was significantly associated with MRSA history, the presence of urinary catheters, percutaneous endoscopic gastrostomy tubes and previous antibiotic therapy, whereas ESBL/ MRGN carriage was exclusively associated with urinary catheters. In conclusion, this study revealed no increase in MRSA prevalence in LTCFs since 2007. In contrast, the rate of ESBL/MRGN carriage in German LTCFs was remarkably high. In nearly all positive residents, MDRO carriage had not been known before, indicating a lack of screening efforts and/or a lack of information on hospital discharge.

\section{Introduction}

Multidrug-resistant organisms (MDRO) are an increasing problem in hospital care worldwide. In Germany, according to data from the Antibiotic Resistance Surveillance System (ARS) and the European Antimicrobial Resistance Surveillance Network (EARSNet) system, the meticillin-resistant Staphylococcus aureus (MRSA) rates have not increased since 2008, with a slight decrease from $22 \%$ in 2010 to $16 \%$ in 2012 in the hospital setting [1-3]. However, an increase in the prevalence of multidrug-resistant Gram-negative organisms (MRGN) has been observed in the past decade $[3,4]$, including a sharp increase in carbapenemresistant organisms (CRO) $[3,5,6]$. MDRO are regarded as a potentially serious threat to elderly people living in long-term care facilities (LTCFs). Although various studies on the prevalence of MRSA in LTCFs in Germany [7-13] and other European countries [14-25] have been published ( $<1 \%$ in the Netherlands and Sweden, > $20 \%$ in Ireland and the United Kingdom (UK)), studies on the prevalence of MRGN such as extended-spectrum betalactamase (ESBL)-producing Enterobacteriaceae and vancomycin-resistant enterococci (VRE) among nursing home residents in German and in European LTCFs are scarce $[7,14,24,26,27]$. Although an increasing trend in the occurrence of ESBL-producing Enterobacteriaceae and even CRO is found in hospitals all over Europe $[1,3,28,29]$, a lack of knowledge on multidrug-resistant organisms (MDRO) in nursing homes has to be stated. Notably, residents of LTCFs may present various risk factors for MDRO carriage and/or transmission (e.g. older age, comorbidities, medical devices or recurrent antibiotic treatments) [30,31]. To issue recommendations for MDRO screening of LTCFs residents, e.g. upon admission to hospital, a better knowledge of current colonisation rates and the most relevant clinical risk factors is needed. The aim of our study was to assess the current prevalence of MDRO, specifically MRSA, ESBL/MRGN and VRE, obtained by case history and by microbiological culture of swabs from nose, throat and perineum. 


\section{Methods}

The study was approved by the Ethics committee of the Chamber of Physicians, County of Hesse, Germany. Inhabitants of 26 LTCFs in the Rhine-Main region were asked to take part in this study and to agree to having swabs from nose, throat and perineum taken for analysis for MDRO. Data on sex, age, health characteristics such as hospital stay, antibiotic therapy during the previous three months and surgery within the past 30 days, current healthcare-associated infection and/ or antibiotic therapy, presence of urinary or vascular catheters, pressure sores and other wounds as well as case history for MDRO were obtained for all participants, using the well-established HALT questionnaire (healthcare-associated infections in LTCFs) in Europe [32]. An identical data set was obtained from non-participants in order to assess potential bias in participation. Information on healthcare-associated infections was obtained according to the McGeer criteria 1990 [33] and adapted by the HALT project, i.e. physician diagnosis of infection had been included as a criterion in all categories of infection in order to avoid underestimation of the infection rate due to lack of on-site diagnostic testing [32].

Anterior bilateral nasal, throat and perianal swabs were collected from April to May 2013 using culture swabs with Amies collection and transport medium (Hain Lifescience, Germany). Swabs from nose, throat and perineum were taken from residents, with their written consent. The swabs from nose and throat were tested for MRSA, while perianal swabs were tested for the presence of VRE and ESBL/MRGN. All specimens were collected by the local nursing personnel. Collected swabs were processed within 24 hours by streaking on Brilliance MRSA 2 agar (Oxoid, Germany), ChromID VRE agar (bioMérieux, Germany) and CHROMagar ESBL (Mast Diagnostics, Germany) for the detection of MRSA, VRE and MRGN including ESBL-producing Enterobacteriaceae, respectively. Definite identification of presumptive $S$. aureus, enterobacterial species and enterococci was confirmed by the VITEK MS matrixassisted laser desorption ionisation time-of-flight mass spectrometry (MALDI-TOF MS) automated system (bioMérieux, Germany). The determination of the antimicrobial susceptibility profiles and classification as ESBL/MRGN, MRSA and VRE was performed by the VITEK 2 identification system (bioMérieux, Germany), using either VITEK N263 (Enterobacteriaceae), P586 (Enterococcus spp.) or $\mathrm{P}_{5} 80$ (Staphylococcus spp.) antimicrobial susceptibility testing (AST) cards according to standard laboratory procedures under strict qualitycontrolled criteria (laboratory accreditation according to DAkkS and DIN15189:2007 standards; certificate number D-ML-13102-01-00, valid through 06.12.2015). MRSA phenotype was confirmed by detection of the mecA gene as described [34]. In addition, PCR for the luk-PV (encoding Panton-Valentine leukocidin) gene was performed as described [35]. MRSA spa-typing was used as first-line typing tool as described previously [36]. We used the BURP algorithm for attribution to clonal complexes (www.ridom.de/staphtype/support). For isolates with spa-types which are not very often detected we used multilocus sequence typing (MLST) according to Enright et al. [37] as well as the S. aureus MLST database (www.mlst.net) for allelic profile analysis. Finally, prevalence rates, Kruskal-Wallis tests and univariate analysis (odds ratios) were performed with SPSS 15 software, IBM, Stanford University, United States (US).

\section{Results}

The total population, i.e. residents present in the 26 homes on the day of the survey, numbered 2,404. Of these residents, 690 (26\%) took part in the MRSA analysis, while only 455 of them (19\%) consented also in anal swabs for analysis of ESBL and MRGN. Characteristics of the total LTCF population and the final study participants are summarised in Table 1. There were no significant differences between participants and non-participants regarding sex, urinary and vascular catheters, pressure sores, impaired mobility, incontinence and disorientation, hospital stay in the past three months, surgery in the past 30 days, current infection or antibiotic therapy. The participants exhibited more 'other wounds', they were older, had more often a percutaneous endoscopic gastrostomy tube than the non-participants, and they had more often been treated with antimicrobials in the previous three months. Prevalence rates of positive MDRO anamnesis were lower in the group of the participants than in the total group (not significant). Prevalence for MDRO in swab cultures exceeded the prevalence of case history for MDRO by far: MRSA $6.5 \%$ vs $0.7 \%$, ESBL $17.8 \%$ vs $0.7 \%$, VRE $0.4 \%$ VS $0 \%$.

From 45 detected MRSA-isolates, only 36, which all were positive for mecA gene but negative for luk-PV gene, could be recultured from stored samples and subjected to spa-typing. Of these 36, 21 were attributed to clonal lineage ST225, 10 to clonal complex 22, four to clonal complex 5 (other than ST225) and one to clonal complex 45. Antibiotic resistance phenotypes of the isolates were typical of those usually observed for MRSA attributed to ST225 and CC22 (resistance to betalactams, erythromycin, clindamycin, fluoroquinolones) [38]. Only one isolate exhibited mupirocin resistance, and three isolates of $\mathrm{ST} 225$ were in addition resistant to fusidic acid.

According to the criteria of the German Commission on Hospital Hygiene and Infection Prevention (KRINKO) [39], Gram-negative pathogens are classified as 3MRGN when resistant to three antibiotic groups (ureidopenicillins, third- and/or fourth-generation cephalosporins and fluoroquinolones) represented by piperacillin, cefotaxime and/or ceftazidime and ciprofloxacin as guiding agents to define resistance for each group. ESBL/MRGN were isolated from swabs from 81 residents; 25 of them tested positive for ESBL and 56 were $3 M R G N$. Among the 25 residents carrying ESBL-producing Enterobacteriaceae, we identified 22 
TABLE 1

Characteristics of residents in 26 nursing homes, prevalence of infections, antibiotic therapy, MDRO anamnesis and colonisation status, Rhine-Main district, Germany, April-May 2013 ( $\mathrm{n}=2,404)$

\begin{tabular}{|c|c|c|c|c|c|}
\hline \multirow{2}{*}{ Population characteristics } & \multicolumn{2}{|c|}{ All residents } & \multicolumn{2}{|c|}{ Participants } & \multirow{2}{*}{$\begin{array}{c}\text { KW test } p \text {-value } \\
\text { participants vs } \\
\text { non-participants }\end{array}$} \\
\hline & $n=2,404$ & $\%$ & $n=690$ & $\%$ & \\
\hline Age $>85$ years $^{a}$ & 1,184 & $49 \cdot 3$ & 369 & 53.5 & 0.009 \\
\hline Male & 679 & 28.2 & 200 & 29.0 & 0.620 \\
\hline Had urinary catheter & 225 & 9.4 & 63 & 9.1 & 0.800 \\
\hline Had vascular catheter & 10 & 0.4 & 4 & 0.6 & 0.430 \\
\hline Had pressure sores & 86 & 3.6 & 28 & 4.1 & 0.424 \\
\hline Had other wounds & 129 & 5.4 & 47 & 6.8 & 0.047 \\
\hline Were disoriented ${ }^{\mathrm{a}}$ & 1,243 & 51.7 & 352 & 51.0 & 0.648 \\
\hline Had impaired mobility & 1,197 & 49.8 & 362 & 52.5 & 0.102 \\
\hline Hospital stay in previous 3 months & 333 & 13.9 & 101 & 14.6 & 0.486 \\
\hline Had surgery in the past 30 days & 37 & 1.5 & 13 & 1.9 & 0.385 \\
\hline Were incontinent & 1,683 & 70.0 & 484 & 70.1 & 0.958 \\
\hline Had percutaneous endoscopic gastrostomy tube & 134 & 5.6 & 55 & 8.0 & 0.001 \\
\hline Had antibiotic therapy during previous 3 months & 309 & 12.9 & 109 & 15.8 & 0.006 \\
\hline Prevalence of all infections & 64 & 2.7 & 18 & 2.6 & 0.914 \\
\hline Prevalence of oral antibiotic therapy & 33 & 1.4 & 6 & 0.9 & 0.178 \\
\hline \multicolumn{6}{|l|}{ Prevalence MDRO vs anamnesis } \\
\hline MRSA & 32 & 1.3 & 5 & 0.7 & 0.099 \\
\hline ESBL & 18 & 0.7 & 5 & 0.7 & 0.929 \\
\hline VRE & 0 & 0 & 0 & 0 & 1 \\
\hline \multicolumn{6}{|l|}{ Prevalence of MDRO colonisation (analysis) } \\
\hline MRSA & NA & NA & 45 & 6.5 & NA \\
\hline ESBL & NA & NA & $81^{b}$ & 17.8 & NA \\
\hline VRE & NA & NA & $2^{\mathrm{b}}$ & 0.4 & NA \\
\hline
\end{tabular}

ESBL: extended-spectrum beta-lactamase; KW: Kruskal-Wallis; MDRO: multidrug-resistant organisms; MRSA: meticillin-resistant

Staphylococcus aureus; NA: not applicable/not available; VRE: vancomycin-resistant enterococci.

a Information missing for one person.

b 455 of 690 participants were tested for ESBL and VRE.

Escherichia coli, two Klebsiella pneumonia, and one Klebsiella oxytoca isolate. Resistance against three antibiotic groups (3MRGN) was detected in $43 \mathrm{E}$. coli, eight $K$. pneumoniae, two Acinetobacter baumannii, one Enterobacter spp. and two Pseudomonas aeruginosa isolates. $4 \mathrm{MRGN}$ (Gram-negative Enterobacteriaceae resistant against four antibiotic groups, namely those mentioned above for 3 MRGN plus resistance to imipenem and/or meropenem) according to the German KRINKO guideline [39] were not detected. Perianal carriage for VRE was observed in two residents (0.4\%).

In 43 of 45 of the residents with MRSA colonisation, the colonisation status was previously unknown. Colonisation in both VRE cases and in 79 of 81 residents positive for ESBL-producing Enterobacteriaceae had not been known before this study either. In three of five residents with a documented MRSA history, detection of MRSA was not confirmed in our study.
In Table 2, patient numbers and odds ratios for MRSA and ESBL colonisation are shown. Medical history for MRSA (OR $=9.9 ; 95 \% \mathrm{Cl}: 1.6-61.1)$, urinary catheter $(\mathrm{OR}=4.2 ; 95 \% \mathrm{Cl}: 2.1-8.7)$, percutaneous endoscopic gastrostomy tube $(\mathrm{OR}=2.7 ; 95 \% \mathrm{Cl}: 1.2-6.2)$ and antibiotic therapy during the last three months $(O R=2.6$; $95 \% \mathrm{Cl}: 1.3-5.1)$ proved to be significantly associated with MRSA colonisation. The odds ratios for ESBL/ MRGN carriage were significantly increased by having a urinary catheter $(\mathrm{OR}=1.9 ; 95 \% \mathrm{Cl}: 1.0-3.8)$. All other characteristics including anamnesis for MDRO (OR>4) proved not to be significant risk factors for ESBL colonisation. One of the two residents with VRE was bedridden and exhibited pressure sores, but neither of them had a catheter or exhibited other risk factors such as a hospital stay during the previous three months. 
TABLE 2

Numbers and odds ratios of nursing home residents with MRSA and with ESBL/MRGN colonisation, Rhine-Main district, Germany, April-May $2013(\mathrm{n}=690)$

\begin{tabular}{|c|c|c|c|c|c|c|c|c|c|c|c|c|}
\hline & \multicolumn{2}{|c|}{$\begin{array}{c}\text { MRSA- } \\
\text { negative } \\
n=645\end{array}$} & \multicolumn{2}{|c|}{$\begin{array}{l}\text { MRSA- } \\
\text { positive } \\
n=45\end{array}$} & \multicolumn{2}{|c|}{ MRSA OR } & \multicolumn{2}{|c|}{$\begin{array}{c}\text { ESBL/MRGN- } \\
\text { negative } \\
n=374\end{array}$} & \multicolumn{2}{|c|}{$\begin{array}{l}\text { ESBL/MRGN- } \\
\text { positive } n=81\end{array}$} & \multicolumn{2}{|c|}{ ESBL/MRGN OR } \\
\hline & $\mathrm{n}$ & $\%$ & $\mathrm{n}$ & $\%$ & OR & $95 \% \mathrm{Cl}$ & $\mathrm{n}$ & $\%$ & $\mathrm{n}$ & $\%$ & OR & $95 \% \mathrm{Cl}$ \\
\hline Aged > 85 yearsa & 343 & 53.2 & 25 & 55.6 & 1.097 & $0.597-2.015$ & 201 & 53.7 & 44 & $54 \cdot 3$ & 1.024 & $0.632-1.658$ \\
\hline Male & 183 & 28.4 & 17 & 37.8 & 1.529 & $0.817-2.862$ & 111 & 29.7 & 18 & 22.2 & 0.677 & $0.383-1.196$ \\
\hline Had urinary catheter & 51 & 7.9 & 12 & 26.7 & 4.228 & $2.058-8.686$ & 36 & 9.6 & 14 & $17 \cdot 3$ & 1.962 & $1.003-3.837$ \\
\hline $\begin{array}{l}\text { Had vascular } \\
\text { catheter }\end{array}$ & 3 & 0.5 & 1 & 2.2 & 4.856 & $0.495-47.652$ & 3 & 0.8 & 0 & 0.0 & 0.821 & $0.786-0.857$ \\
\hline Had pressure sores & 24 & 3.7 & 4 & 8.9 & 2.520 & $0.835-7.607$ & 18 & 4.8 & 3 & 3.7 & 0.761 & $0.219-2.646$ \\
\hline Had other wounds & 41 & 6.4 & 6 & $13 \cdot 3$ & 2.263 & $0.905-5.654$ & 29 & 7.8 & 7 & 8.6 & 1.125 & $0.475-2.667$ \\
\hline Were disorienteda & 323 & 50.1 & 28 & 62.2 & 1.637 & $0.879-3.049$ & 199 & 53.2 & 48 & $59 \cdot 3$ & 1.279 & $0.786-2.083$ \\
\hline $\begin{array}{l}\text { Had impaired } \\
\text { mobility }\end{array}$ & 332 & 51.5 & 30 & 66.7 & 1.880 & $0.992-3.560$ & 197 & 52.7 & 52 & 64.2 & 1.611 & $0.980-2.650$ \\
\hline $\begin{array}{l}\text { Had hospital stay in } \\
\text { previous } 3 \text { months }\end{array}$ & 95 & $14 \cdot 7$ & 6 & $13 \cdot 3$ & 0.889 & $0.366-2.158$ & 61 & 16.3 & 9 & 11.1 & 0.641 & $0.304-1.351$ \\
\hline $\begin{array}{l}\text { Had surgery in the } \\
\text { past } 30 \text { days }\end{array}$ & 13 & 2.0 & 0 & 0.0 & 0.933 & $0.915-0.952$ & 5 & 1.3 & 3 & 3.7 & 2.838 & $0.664-12.125$ \\
\hline Were incontinent & 453 & 70.2 & 31 & 68.9 & 0.934 & $0.486-1.794$ & 254 & 67.9 & 61 & $75 \cdot 3$ & 1.441 & $0.832-2.497$ \\
\hline $\begin{array}{l}\text { Had percutaneous } \\
\text { endoscopic } \\
\text { gastrostomy tube }\end{array}$ & 47 & $7 \cdot 3$ & 8 & 17.8 & 2.746 & $1.210-6.235$ & 34 & 9.1 & 13 & 16.0 & 1.912 & $0.959-3.812$ \\
\hline $\begin{array}{l}\text { Had antibiotic } \\
\text { therapy during } \\
\text { previous } 3 \text { months }\end{array}$ & 95 & 14.7 & 14 & 31.1 & 2.610 & $1.339-5.088$ & 61 & 16.3 & 10 & 12.3 & 0.723 & $0.353-1.480$ \\
\hline $\begin{array}{l}\text { Prevalence of all } \\
\text { infections }\end{array}$ & 15 & 2.3 & 3 & 6.7 & 2.995 & $0.834-10.755$ & 12 & 3.2 & 3 & 3.7 & 1.160 & $0.320-4.209$ \\
\hline $\begin{array}{l}\text { Prevalence of oral } \\
\text { antibiotic therapy }\end{array}$ & 6 & 0.9 & 0 & 0.0 & 0.934 & $0.916-0.953$ & 4 & 1.1 & 0 & 0.0 & 0.820 & $0.786-0.857$ \\
\hline \multicolumn{13}{|c|}{ Prevalence MDRO vs anamnesis } \\
\hline MRSA & 3 & 0.5 & 2 & 4.4 & 9.938 & $1.617-61.069$ & 2 & 0.5 & 2 & 2.5 & $4 \cdot 709$ & $0.653-33.933$ \\
\hline ESBL & 5 & 0.8 & 0 & 0.0 & 0.934 & $0.916-0.953$ & 1 & 0.3 & 1 & 1.2 & 4.663 & $0.289-75.329$ \\
\hline VRE & 0 & 0 & 0 & 0 & NA & NA & 0 & 0.0 & 0 & 0.0 & NA & NA \\
\hline
\end{tabular}

$\mathrm{Cl}$ : confidence interval; ESBL: extended-spectrum beta-lactamase; MDRO: multidrug-resistant organisms; MRSA: meticillin-resistant Staphylococcus aureus; NA: not analysed; OR: odds ratio; VRE: vancomycin-resistant enterococci.

a Information missing for one person.

\section{Discussion}

Our point prevalence study on MDRO such as MRSA, ESBL/MRGN and VRE in residents of LTCFs in the RhineMain district in Germany revealed a high MRSA prevalence compared with hospital settings, rehabilitation and dialysis units in Germany [40], and a much higher prevalence for ESBL/MRGN carriage, whereas VRE had a very low prevalence in the studied LTCFs.

Our study has the following limitations: Of the 214 LTCFS located in in the Rhine-Main district, the 83 members of the MDRO-network Rhine-Main were asked to participate and 26 of them finally participated in this study. With informed consent being necessary for investigation of MDRO colonisation in nursing home residents in Germany, we were able to enrol only 690 (29\%) of all residents in the MRSA study and $455(19 \%)$ in the
ESBL/MRGN study. Our study has features of cluster sampling, which could lead to wider confidence intervals. Participants had significantly more often reported on antibiotic therapy in the past three months than non-participants and were more often supplied with a percutaneous endoscopic gastrostomy tube. However, no significant differences between participants and non-participants were found regarding sex, impaired mobility, disorientation, faecal or urinary incontinence, urinary and vascular catheter etc. Residents with a positive case history for MRSA, ESBL or VRE were not represented more than other residents in the MDRO analysis. Therefore, the hypothesis that residents with positive MDRO anamnesis may take advantage of the opportunity to receive an MDRO analysis free of charge and thus would be overrepresented in the study did not prove to be true. Thus, although the number of 
TABLE 3

MDRO in residents of long-term care facilities in Frankfurt am Main compared with other studies in Germany and abroad 2000-13

\begin{tabular}{|c|c|c|c|c|c|c|c|}
\hline \multirow{2}{*}{ Country } & \multirow{2}{*}{$\begin{array}{c}\text { Year of } \\
\text { investigation }\end{array}$} & \multirow{2}{*}{$\begin{array}{c}\text { LTCFs } \\
n\end{array}$} & \multirow{2}{*}{$\begin{array}{c}\text { Residents tested } \\
n\end{array}$} & \multirow{2}{*}{$\begin{array}{c}\text { MRSA } \\
\%\end{array}$} & \multirow{2}{*}{$\begin{array}{c}\text { ESBL } \\
\%\end{array}$} & \multirow{2}{*}{$\begin{array}{c}\text { VRE } \\
\%\end{array}$} & \multirow{2}{*}{ Reference } \\
\hline & & & & & & & \\
\hline \multicolumn{8}{|l|}{ Germany } \\
\hline Different regions & 2000 & 32 & 1,342 & 2.4 & NR & NR & {$[8]$} \\
\hline Frankfurt am Main & 2000 & 8 & $159^{\mathrm{a}}$ & 2.5 & NR & NR & [8] \\
\hline Heidelberg & $2000 / 01$ & 47 & 3,236 & 1.1 & NR & NR & [13] \\
\hline North Rhine-Westphalia & $2000 / 01$ & 30 & 1,057 & 3.1 & NR & NR & {$[11]$} \\
\hline Frankfurt am Main & 2001 & 6 & 319 & 0.3 & NR & NR & [9] \\
\hline Frankfurt am Main & 2007 & 8 & 178 & 9.0 & 11.2 & 0 & {$[7]$} \\
\hline Hessen & $2010 / 11$ & 11 & 240 & NR & 9.6 & NR & {$[27]$} \\
\hline Brunswick & 2011 & 32 & 1,827 & 7.6 & NR & NR & {$[12]$} \\
\hline Frankfurt am Main & 2012 & 8 & 184 & 9.2 & 26.7 & 2.7 & {$[10]$} \\
\hline \multicolumn{8}{|l|}{ Europe } \\
\hline France & 2004 & 1 & 109 & 37.6 & NR & NR & [20] \\
\hline Slovenia & 2005 & 1 & 107 & 9.3 & NR & NR & {$[18]$} \\
\hline Belgium & 2005 & 60 & 2,953 & 19.9 & NR & NR & {$[19]$} \\
\hline Spain & 2005 & 9 & 1,377 & 16.8 & NR & NR & [23] \\
\hline Italy & 2006 & 2 & 551 & 7.8 & NR & NR & {$[17]$} \\
\hline United Kingdom & 2007 & 39 & 715 & 22.0 & NR & NR & {$[16]$} \\
\hline Ireland & 2007 & 45 & 1,111 & 23.3 & NR & NR & {$[15]$} \\
\hline Italy & 2008 & 1 & 120 & 38.7 & 64 & NR & {$[24]$} \\
\hline Spain & $2009 / 10$ & 17 & 744 & 10.6 & NR & NR & {$[21]$} \\
\hline Luxembourg & 2010 & 19 & 954 & 7.2 & NR & NR & {$[25]$} \\
\hline Sweden & 2010 & 9 & 495 & 0 & 3.0 & 0 & {$[14]$} \\
\hline United States & 1998 & 1 & 117 & 24 & 33 & $3 \cdot 5$ & {$[45]$} \\
\hline Australia & 2000 & 8 & 292 & NR & NR & 3.1 & {$[55]$} \\
\hline United States & 2008 & 1 & 84 & 28 & 51 & 4 & [43] \\
\hline United States & NR & 1 & 160 & 27.5 & NR & NR & {$[41]$} \\
\hline United States, California & $2008 / 09$ & NR & 1,000 & 30.7 & NR & NR & [44] \\
\hline Australia, Melbourne & 2010 & 3 & 119 & NR & 12 & 2 & {$[52]$} \\
\hline United States & $2006 / 07$ & 1 & 161 & 11.8 & 22.8 & 0.6 & [42] \\
\hline China & 2011 & 40 & 2,020 & 21.6 & NR & NR & [46] \\
\hline
\end{tabular}

ESBL: extended-spectrum beta-lactamase; LTCF: long-term care facility; MDRO: multidrug-resistant organisms; MRSA: meticillin-resistant Staphylococcus aureus; NR: not reported (in the main text or abstract only); VRE: vancomycin-resistant enterococci.

a Residents were a subgroup of 1,342 residents tested by Heuck et al. [8] all over Germany, 2000.

b 455 of them were tested for both ESBL and VRE.

participating LTCFs and the response rate of $29 \%(19 \%$ for the ESBL study) among residents was rather low, there is no obvious indication for bias in our study, so that the data can be regarded as representative for LTCFs in the Rhine-Main region in Germany in 2013.

The point prevalence of MRSA colonisation was $6.5 \%$ and thus much higher than in earlier studies in 200001 in Germany $[8,9,11,13]$, but since 2007 , the MRSA prevalence in LTCFs in Germany has not increased further and remained between $6.5 \%$ and $9.2 \%[7,10,12]$.
The MRSA prevalence we observed was lower than in MRSA surveys in recent years in the US [41-45], China [46], the UK [16], France [20], Ireland [15], and Italy [24], but higher than in the Netherlands and Sweden $[14,22]$ (Table 3).

All MRSA isolates were attributed to clonal lineages (ST) and/or clonal complexes (CC) that are prevalent in German hospitals, in particular ST225 is widely disseminated in the west of Germany [47]. These results indicate primary hospital origin. Prevalence of these 
clonal lineages was also reported in a study from 2006 in the west of Germany bordering the Netherlands [48]. None of the isolates reported here were attributed to community-associated MRSA (CA-MRSA) or livestockassociated MRSA (LA-MRSA). That CA-MRSA can represent a substantial proportion of MRSA in nursing home residents has been reported from the US [49], and LA-MRSA has been identified among isolates from Dutch nursing homes [50]. In Germany, CA-MRSA is not common so far, nor is LA-MRSA as nasal coloniser and infectious agent in regions of Germany with low density of livestock farming such as the Rhine-Main region [51]. As all our isolates were susceptible to antibiotics that are recommended as treatment alternatives for MRSA infections, e.g. vancomycin, teicoplanin, linezolid, daptomycin, tigecycline, rifampicin and cotrimoxazol, calculated therapy of severe infections should be unproblematic.

Regarding ESBL and VRE carriage, only two other studies in German LTCFs, not done in Frankfurt am Main $[7,10]$, have been published since 1999 [26,27]. ESBL/ MRGN prevalence in our studies was $11.2 \%$ up to $26.7 \%$ $[7,10]$ and therefore much higher than MRSA prevalence. Three studies from LTCFs in the US and one in Italy exhibited higher prevalence rates for ESBL-producing bacteria than our study $[24,42,43,45]$, whereas in Australian and especially in Swedish LTCFs, ESBL prevalence rates were lower than in the Rhine-Main region [14,52] (Table 3). However, in all studies, ESBL rates exceeded those of MRSA by far [7,10,24,42,43,45]. Prevalence rates of MRSA and ESBL/MRGN in the LTCF residents in our study were even higher than those in a survey on 750 ambulatory patients undergoing haemodialysis enrolled in the Rhine-Main area in summer 2012, presenting 2.1\% MRSA, 7.5\% ESBL and 5.5\% VRE prevalence [53].

Compared with studies on MRSA in LTCFs, only few studies on ESBL/MRGN have been published so far, with a maximum of 495 participants per study. Our study encompassing 455 participants was a comparatively large study. In Germany, up to now, MDRO prevalence rates in residents from nursing homes have only been published for the Rhine-Main region $[7,10]$ and the federal state of Hesse [27]. This is striking because of the well-known and published increase in MRGN in the hospital setting in Germany and abroad.

In Germany, guidelines for hygiene and infection prevention in LTCFs have been published in 2005 [51], including recommendations for the care of residents with MRSA colonisation. According to these guidelines, isolation of those persons is recommended for hospitals but does not need to be applied in LTCFs. A single room (no isolation), however, is recommended if the resident with MRSA colonisation or their roommate exhibits risk factors such as medical devices or wounds. In 2012, KRINKO published a guideline on the management of patients carrying 3MRGN and 4 MRGN [39]. It recommends that patients with $3 M R G N$ are isolated in risk areas such as intensive care units only, whereas patients with 4 MRGN must be cared for in single rooms in combination with barrier nursing in all hospital wards. Although the guideline primarily addresses the hospital setting, the KRINKO expert panel recommends that in other healthcare settings such as LTCFs, hygienic measurements for MRGN should not exceed those defined for MRSA [39]. Therefore, a high standard of hygiene should be applied to residents with ESBL/MRGN, but restriction of their mobility in the home and their contact to other residents is not necessary. Staff, however, need to be well informed about new and emerging antibiotic-resistant organisms and must observe good hygiene for the protection of other residents and themselves. Although $4 \mathrm{MRGN}$ have as yet not been detected in the residents in our studies, it can be hypothesised that this may soon be the case as 4 MRGN rates are continuously increasing in Germany and Europe [54].

In conclusion, the data suggest that MRSA prevalence in LTCFs in the Rhine-Main region is stable, but a high ESBL/MRGN carriage in LTCFs is recognised. No CRO have been detected yet. In nearly all residents with MDRO, the MDRO carriage had not been known before, indicating a lack of screening and/or a lack of information on hospital discharge.

\section{Acknowledgments}

The study has been approved by funded by the German Ministry of Health, Bonn, Germany, the Hessian Ministry of Health, Wiesbaden, Germany, and by the Willy Robert Pitzer Foundation, Bad Nauheim, Germany.

\section{Conflict of interest}

None declared.

\section{Authors' contributions}

PP, DM and UH were responsible for the study design, statistical analysis, and did the literature search. MH, PP, DM, CC, VAK and UH contributed to data collection and analysis as well as writing and review of the manuscript.

\section{References}

1. European Centre for Disease Prevention and Control (ECDC). Antimicrobial resistance surveillance in Europe 2011. Annual report of the European Antimicrobial Resistance Surveillance Network (EARS-Net). Stockholm: ECDC; 2012. Available from: http://ecdc.europa.eu/en/ publications/_layouts/forms/Publication DispForm. aspx? List $=4$ f55ad51-4aed-4d32-b96o-af $70113 \mathrm{dbb} 90 \& \mathrm{ID}=719$

2. Layer F, Cuny C, Strommenger B, Werner G, Witte W. [Current data and trends on methicillin-resistant Staphylococcus aureus (MRSA)]. Bundesgesundheitsblatt Gesundheitsforschung Gesundheitsschutz. 2012;55(11-12):1377-86. German. http:// dx.doi.org/10.1007/s00103-012-1560-x PMID:23114436

3. Noll I, Schweickert B, Abu Sin M, Feig M, Claus H, Eckmanns T. [Antimicrobial resistance in Germany. Four years of antimicrobial resistance surveillance (ARS)]. Bundesgesundheitsblatt Gesundheitsforschung Gesundheitsschutz. 2012;55(11-12):1370-6. German. http:// dx.doi.org/10.1007/s00103-012-1559-3 PMID:23114435 
4. Meyer E, Schwab F, Schroeren-Boersch B, Gastmeier P. Dramatic increase of third-generation cephalosporin-resistant E. coli in German intensive care units: secular trends in antibiotic drug use and bacterial resistance, 2001 to 2008. Crit Care. 2010;14(3):R113. PMID:20546564

5. Glasner C, Albiger B, Buist G, Tambić Andrasević A, Canton R, Carmeli Y, et al. Carbapenemase-producing Enterobacteriaceae in Europe: a survey among national experts from 39 countries, February 2013. Euro Surveill. 2013;18(28):20525. Available from: http://dx.doi.org/10.2807/1560-7917.ES2013.18.28.20525 PMID:23870096

6. Nordmann P, Naas T, Poirel L. Global spread of carbapenemase-producing Enterobacteriaceae. Emerg Infect Dis. 2011;17(10):1791-8. Available from: http://dx.doi. org/10.3201/eid1710.110655 PMID:22000347

7. Gruber I, Heudorf U, Werner G et al. Multidrug-resistant bacteria in geriatric clinics, nursing homes, and ambulant care - prevalence and risk factors. International Journal of Medical Microbiology, 2013;10.pii: S1438-4221(13)00066-0.

8. Heuck D, Witte W. Methicillin-resistente Staphylococcus aureus (MRSA) in deutschen Alten- und Pflegeheimen - zur Situation. [Methicillin-resistant Staphylococcus aureus (MRSA) in German long-term care facilities - current situation. Epidemiologisches Bulletin. 2003;19:145-8. German. Available from: http://www.rki.de/DE/Content/Infekt/EpidBull/ Archiv/2003/Ausgabenlinks/19_03.pdf;jsessionid=8A4F71E63 AA40329C7307A440E19C6D9.2_cid390?_blob=publicationFile

9. Heudorf U, Bremer V, Heuck D, Brune I, Wichelhaus TA. [MRSA prevalence in residents of long-term care facilities as well an in a rehabilitation unit]. MRSA-Prävalenz bei Bewohnern von Alten- und Pflegeheimen sowie bei Patienten einer geriatrischen Rehabilitationsklinik. Hygiene und Medizin. Hygiene und Medizin. 2002;27:16-9. German.

10. Heudorf U, Gustav G, Mischler D, Schulze J. [Healthcare associated infections ( $\mathrm{HAl}$ ), antibiotic use and prevalence of multidrug-resistant bacteria (MDRO) in residents of longterm care facilities: the Frankfurt HALT plus MDRO project 2012]. Bundesgesundheitsblatt Gesundheitsforschung Gesundheitsschutz. 2014;57:414-22, German. http://dx.doi. org/10.1007/s00103-013-1927-7. PMID:24658671

11. Neuhaus B, Bocter N, Braulke C, Heuck D, Witte W. [Study on the occurrence of methicillin-resistant Staphylococcus aureus in nursing homes in North Rhine-Westphalia]. Studie zum Vorkommen von Methicillin-resistenten Staphylococcus aureus in Alten- und Altenpflegeheimen in NordrheinWestfalen. Bundesgesundheitsblatt Gesundheitsforschung Gesundheitsschutz. 2002;45(11):894-904. German. http:// dx.doi.org/10.1007/s00103-002-0521-1

12. Pfingsten-Würzburg S, Pieper DH, Bautsch W, Probst-Kepper M. Prevalence and molecular epidemiology of meticillinresistant Staphylococcus aureus in nursing home residents in northern Germany. J Hosp Infect. 2011;78(2):108-12. Available from: http://dx.doi.org/10.1016/j.jhin.2011.02.011 PMID:21481969

13. von Baum H, Schmidt C, Svoboda D, Bock-Hensley O, Wendt C. Risk factors for methicillin-resistant Staphylococcus aureus carriage in residents of German nursing homes. Infect Control Hosp Epidemiol. 2002;23(9):511-5.http://dx.doi. org/10.1086/502098 PMID:12269448

14. Andersson H, Lindholm C, Iversen A, Giske CG, Örtqvist $\AA$, Kalin $M$, et al. Prevalence of antibiotic-resistant bacteria in residents of nursing homes in a Swedish municipality: healthcare staff knowledge of and adherence to principles of basic infection prevention. Scand J Infect Dis. 2012;44(9):641 9. Available from: http://dx.doi.org/10.3109/00365548.2012.67 1956 PMID:22680834

15. Baldwin NS, Gilpin DF, Hughes CM, Kearney MP, Gardiner DA, Cardwell C, et al. Prevalence of methicillin-resistant Staphylococcus aureus colonization in residents and staff in nursing homes in Northern Ireland. J Am Geriatr Soc. 2009;57(4):620-6. Available from: http://dx.doi.org/10.1111/ j.1532-5415.2009.02181.x PMID:19392953

16. Barr B, Wilcox MH, Brady A, Parnell P, Darby B, Tompkins D. Prevalence of methicillin-resistant Staphylococcus aureus colonization among older residents of care homes in the United Kingdom. Infect Control Hosp Epidemiol. 2007;28(7):8539. Available from: http://dx.doi.org/10.1086/516795 PMID:17564989

17. Brugnaro P, Fedeli U, Pellizzer G, Buonfrate D, Rassu M, Boldrin C, et al. Clustering and risk factors of methicillinresistant Staphylococcus aureus carriage in two Italian long-term care facilities. Infection. 2009;37(3):216-21. Available from: http://dx.doi.org/10.1007/S15010-008-8165-1 PMID:19148574

18. Cretnik TZ, Vovko P, Retelj M, Jutersek B, Harlander T, Kolman J, et al. Prevalence and nosocomial spread of methicillinresistant Staphylococcus aureus in a long-term-care facility in
Slovenia. Infect Control Hosp Epidemiol. 2005;26(2):184-90. http://dx.doi.org/10.1086/502524 PMID:15756890

19. Denis O, Jans B, Deplano A, Nonhoff C, De Ryck R, Suetens C, et al. Epidemiology of methicillin-resistant Staphylococcus aureus (MRSA) among residents of nursing homes in Belgium. J Antimicrob Chemother. 2009;64(6):1299-306. Available from: http://dx.doi.org/10.1093/jac/dkp345 PMID:19808236

20. Eveillard M, Charru P, Rufat P, Hippeaux MC, Lancien E, Benselama F, et al. Methicillin-resistant Staphylococcus aureus carriage in a long-term care facility: hypothesis about selection and transmission. Age Ageing. 2008;37(3):294-9. Available from: http://dx.doi.org/10.1093/ageing/afno21 PMID:18270245

21. García-García JA, Santos-Morano J, Castro C, Bayoll-Serradilla E, Martín-Ponce ML, Vergara-López S, et al. [Prevalence and risk factors of methicillin-resistant Staphylococcus aureus colonization among residents living in long-term care facilities in southern Spain]. Enferm Infecc Microbiol Clin. 2011;29(6):405-10. German. PMID:21349606

22. Greenland K, Rijnders MI, Mulders M, Haenen A, Spalburg $E$, van de Kassteele J, et al. Low prevalence of methicillinresistant Staphylococcus aureus in Dutch nursing homes. I Am Geriatr Soc. 2011;59(4):768-9.http://dx.doi.org/10.1111/j.15325415.2011.03325.x PMID:21492112

23. Manzur A, Gavalda L, Ruiz de Gopegui E, Mariscal D, Dominguez MA, Perez JL, et al. Prevalence of methicillinresistant Staphylococcus aureus and factors associated with colonization among residents in community long-term-care facilities in Spain. Clin Microbiol Infect. 2008;14(9):86772. Available from: http://dx.doi.org/10.1111/j.14690691.2008.02060.x PMID:18844688

24. March A, Aschbacher R, Dhanji H, Livermore DM, Böttcher $A$, Sleghel F, et al. Colonization of residents and staff of a long-term-care facility and adjacent acute-care hospital geriatric unit by multiresistant bacteria. Clin Microbiol Infect. 2010;16(7):934-44. Available from: http://dx.doi.org/10.1111/ j.1469-0691.2009.03024.x PMID:19686277

25. Mossong J, Gelhausen E, Decruyenaere F, Devaux A, Perrin $M$, Even J, et al. Prevalence, risk factors and molecular epidemiology of methicillin-resistant Staphylococcus aureus (MRSA) colonisation in residents of long-term care facilities in Luxembourg, 2010. Epidemiol Infect. 2013;141(6):1199-206. PMID:22953727

26. Wendt C, Krause C, Xander LU, Löffler D, Floss H. Prevalence of colonization with vancomycin-resistant enterococci in various population groups in Berlin, Germany. J Hosp Infect. 1999;42(3):193-200. Available from: http://dx.doi.org/10.1053/ jhin.1999.0597 PMID:10439991

27. Arvand M, Moser V, Pfeifer Y. Prevalence of extendedspectrum- $\beta$-lactamase-producing Escherichia coli and spread of the epidemic clonal lineage ST131 in nursing homes in Hesse, Germany. J Antimicrob Chemother. 2013;68(11):26868. Available from: http://dx.doi.org/10.1093/jac/dkt226 PMID:23759669

28. Cantón R, Novais A, Valverde A, Machado E, Peixe L, Baquero $F$, et al. Prevalence and spread of extended-spectrum beta-lactamase-producing Enterobacteriaceae in Europe. Clin Microbiol Infect. 2008;14(Suppl 1):144-53. Available from: http://dx.doi.org/10.1111/j.1469-0691.2007.01850.x PMID:18154538

29. Livermore DM, Canton R, Gniadkowski M, Nordmann P, Rossolini GM, Arlet G, et al. CTX-M: changing the face of ESBLs in Europe. J Antimicrob Chemother. 2007;59(2):16574. Available from: http://dx.doi.org/10.1093/jac/dkl483 PMID:17158117

30. 30. Murphy CR, Quan V, Kim D, Peterson E, Whealon M, Tan G, et al. Nursing home characteristics associated with methicillinresistant Staphylococcus aureus (MRSA) Burden and Transmission. BMC Infect Dis. 2012;12(1):269.http://dx.doi. org/10.1186/1471-2334-12-269 PMID:23095678

31. Murphy CR, Eells SJ, Quan V, Kim D, Peterson E, Miller LG, et al. Methicillin-resistant Staphylococcus aureus burden in nursing homes associated with environmental contamination of common areas. J Am Geriatr Soc. 2012;6o(6):1012-8. Available from: http://dx.doi.org/10.1111/j.1532-5415.2012.03978.x PMID:22670708

32. Latour K, Jans B, HALT management team. Healthcare associated infections in long-term care facilities. Results of the pilot point prevalence survey. November 2009. Deposit number D/2011/2505/8; IPH/Epi-report number: 2011-006. Available from: http://halt.wiv-isp.be/report/Reports/HALT-1/HALT\%20 Report\%20Pilot\%20Survey\%20Nov\%202009.pdf

33. McGeer A, Campbell B, Emori TG, Hierholzer WJ, Jackson MM, Nicolle LE, et al. Definitions of infection for surveillance in long-term care facilities. Am J Infect Control. 1991;19(1):1-7. http://dx.doi.org/10.1016/0196-6553(91)90154-5 PMID:1902352 
34. Cuny C, Pasemann B, Witte W. Detection of oxacillin resistance in Staphylococcus aureus by screening tests. Eur J Clin Microbiol Infect Dis. 1999;18(11):834-6.http://dx.doi. org/10.1007/s100960050413 PMID:10614964

35. Lina G, Piémont Y, Godail-Gamot F, Bes $M$, Peter MO, Gauduchon V, et al. Involvement of Panton-Valentine leukocidin-producing Staphylococcus aureus in primary skin infections and pneumonia. Clin Infect Dis. 1999;29(5):112832. Available from: http://dx.doi.org/10.1086/313461 PMID:10524952

36. Cuny C, Nathaus R, Layer F, Strommenger B, Altmann D, Witte W. Nasal colonization of humans with methicillin-resistant Staphylococcus aureus (MRSA) CC398 with and without exposure to pigs. PLoS ONE. 2009;4(8):e6800. Available from: http://dx.doi.org/10.1371/journal.pone.0006800 PMID:19710922

37. Enright MC, Robinson DA, Randle G, Feil EJ, Grundmann $\mathrm{H}$, Spratt BG. The evolutionary history of methicillinresistant Staphylococcus aureus (MRSA). Proc Natl Acad Sci USA. 2002;99(11):7687-92. Available from: http://dx.doi. org/10.1073/pnas.122108599 PMID:12032344

38. Witte W, Cuny C, Klare I, Nübel U, Strommenger B, Werner G. Emergence and spread of antibiotic-resistant Gram-positive bacterial pathogens. Int J Med Microbiol. 2008;298(56):365-77.http://dx.doi.org/10.1016/j.ijmm.2007.10.005 PMID:18325835

39. KRINKO. [Hygiene measures for infection or colonization with multidrug-resistant gram-negative bacilli. Commission recommendation for hospital hygiene and infection prevention (KRINKO) at the Robert Koch Institute (RKI)]. Bundesgesundheitsblatt Gesundheitsforschung Gesundheitsschutz. 2012;55(10):1311-54. German. PMID:23011096

40. KRINKO. [Recommendations for prevention and control of methicillin-resistant staphylococcus aureus (MRSA) in medical and nursing facilities]. Bundesgesundheitsblatt Gesundheitsforschung Gesundheitsschutz. 2014;57:696-732. German. PMID:24987771

41. Garazi M, Edwards B, Caccavale D, Auerbach C, Wolf-Klein G. Nursing homes as reservoirs of MRSA: myth or reality? J Am Med Dir Assoc. 2009;10(6):414-8. Available from: http://dx.doi. org/10.1016/j.jamda.2009.02.014 PMID:19560719

42. O'Fallon E, Pop-Vicas A, D'Agata E. The emerging threat of multidrug-resistant gram-negative organisms in long-term care facilities. J Gerontol A Biol Sci Med Sci. 2009;64(1):138 41. Available from: http://dx.doi.org/10.1093/gerona/glno20 PMID:19164271

43. Pop-Vicas A, Mitchell SL, Kandel R, Schreiber R, D’Agata EM. Multidrug-resistant gram-negative bacteria in a long-term care facility: prevalence and risk factors. J Am Geriatr Soc. 2008;56(7):1276-80. Available from: http://dx.doi.org/10.1111/ j.1532-5415.2008.01787.x PMID:18557965

44. Reynolds C, Quan V, Kim D, Peterson E, Dunn J, Whealon M, et al. Methicillin-resistant Staphylococcus aureus (MRSA) carriage in 10 nursing homes in Orange County, California. Infect Control Hosp Epidemiol. 2011;32(1):91-3.http://dx.doi. org/10.1086/657637 PMID:21087124

45. Trick WE, Weinstein RA, DeMarais PL, Kuehnert MJ, Tomaska W, Nathan C, et al. Colonization of skilled-care facility residents with antimicrobial-resistant pathogens. J Am Geriatr Soc. 2001;49(3):270-6. Available from: http://dx.doi. org/10.1046/j.1532-5415.2001.4930270.x PMID:11300237

46. Cheng VC, Tai JW, Wong ZS, Chen JH, Pan KB, Hai Y, et al. Transmission of methicillin-resistant Staphylococcus aureus in the long term care facilities in Hong Kong. BMC Infect Dis. 2013;13:205. Available from: http://dx.doi. org/10.1186/1471-2334-13-205PMID:23641974

47. van der Donk CF, Schols JM, Schneiders V, Grimm KH, Stobberingh EE. Antibiotic resistance, population structure and spread of Staphylococcus aureus in nursing homes in the Euregion Meuse-Rhine. Eur J Clin Microbiol Infect Dis. 2013;32(11):1483-9. Available from: http://dx.doi.org/10.1007/ S10096-013-1901-1 PMID:23733319

48. Köck R, Brakensiek L, Mellmann A, Kipp F, Kim F, Henderikx $M$, et al. Cross-border comparison of the admission prevalence and clonal structure of meticillin-resistant Staphylococcus aureus. J Hosp Infect. 2009;71(4):320-6. http://dx.doi. org/10.1016/j.jhin.2008.12.001. PMID:19201056

49. Murphy CR, Hudson LO, Spratt BG, Quan V, Kim D, Peterson $E$, et al. Predicting high prevalence of community methicillinresistant Staphylococcus aureus strains in nursing homes. Infect Control Hosp Epidemiol. 2013;34(3):325-6. Available from: http://dx.doi.org/10.1086/669519 PMID:23388372

50. Verkade E, Bosch T, Hendriks Y, Kluytmans J. Outbreak of methicillin-resistant Staphylococcus aureus ST398 in a Dutch nursing home. Infect Control Hosp Epidemiol.
2012;33(6):624-6. Available from: http://dx.doi. org/10.1086/665726 PMID:22561720

51. KRINKO. [Infection prevention in the home. Recommendations of the Commission for Hospital Hygiene and Infection Production of the Robert Koch Institute (RKI)]. Bundesgesundheitsblatt Gesundheitsforschung Gesundheitsschutz. 2005;48(9):1061-80. German. PMID:16160897

52. Stuart RL, Kotsanas D, Webb B, Vandergraaf S, Gillespie EE, Hogg GG, et al. Prevalence of antimicrobial-resistant organisms in residential aged care facilities. Med J Aust. 2011;195(9):5303.http://dx.doi.org/10.5694/mja11.10724 PMID:22060088

53. Dawson A, Mischler D, Petit C, Klein R, Heudorf U, Herrmann M. Prevalence of methicillin-resistant Staphylococcus aureus in end stage renal failure patients in Saarland and Hessen. Int J Med Microbiol. 2012;302:87.

54. European Centre for Disease Prevention and Control (ECDC). Antimicrobial resistance surveillance in Europe 2013. Annual report of the European Antimicrobial Resistance Surveillance Network (EARS-Net). Stockholm: ECDC; 2014. Available from: http://ecdc.europa.eu/en/publications/Publications/ antimicrobial-resistance-surveillance-europe-2013.pdf

55. Padiglione AA, Grabsch E, Wolfe R, Gibson K, Grayson ML. The prevalence of fecal colonization with VRE among residents of long-term-care facilities in Melbourne, Australia. Infect Control Hosp Epidemiol. 2001;22(9):576-8. Available from: http:// dx.doi.org/10.1086/501955 PMID:11732788 